\title{
Perceptions of Dairy Farmers of Gadag district in northwestern part of Karnataka state, India regarding Clean Milk Production
}

\author{
Shivakumar K. Radder* and S.K. Bhanj \\ Dept. of Veterinary \& Animal Husbandry Extension, \\ Veterinary College, KVAFSU, Nandinagar, Bidar - 585 401, Karnataka, India. \\ * Corresponding author email : shiva_vet2002@yahoo.co.in
}

\begin{abstract}
Clean milk production is one important aspect in enhancing the quality of milk. It is important to know farmers' perception about it. With this view, present study was undertaken with the objective of understanding perception of dairy farmers about clean milk production. The study was conducted in six villages of Gadag district of Karnataka state. A total of 180 respondents were interviewed. Perceptions of the farmers regarding family manpower involved in dairy farming, personnel involved in milking, dairy income, intention to produce clean milk, price dependence for following clean milk production, reasons for following cleanliness measures in milk production, sale price received for milk and satisfaction for the price they received for milk were studied. Most of the dairy farmers expressed their willingness to follow clean milk production measures. Further, most of them were ready to follow such measures even if they were not paid more price for milk. Farmers practiced clean milk production measures mainly to follow regulations at the dairy co-operative society followed by to avoid spoilage of milk. Dairy farmers largely neglected impact of cleanliness on animals' udder and health, about milk contamination causing health hazards. Milking was mainly a domain of women. For over $80 \%$ farmers, dairy farming provided a moderate income as portion of their total family income. Majority of the producers were not satisfied with price they were getting for milk. Hence, the study recommends, requisite facilities and guidelines from the agencies concerned are needed to be provided to the dairy farmers to adopt clean milk production practices. Proper education to the farmers regarding importance of clean milk production from health, marketing and animal health point of views needs to be given. There is need to give more importance to women in dairy farmers' trainings. The study also suggests offering satisfactory price for milk to hasten the process of adoption of clean milk production practices by the dairy farmers.
\end{abstract}

Key words : Dairy Farmers, Clean Milk Production, Co-operative society, Milk Contamination.

\section{Introduction}

Dairying forms a major component of livestock sector in India. India being the highest producer of milk in the world has great potentiality to tap of the emerging global marketing opportunities. There is a lot of potential in India to increase milk production. No doubt, India has made rapid strides in enhancing the quantity of milk produced. But, it is lagging behind with regard to quality.

Major constituents for milk production in dairy industry in India are small, and marginal farmers and unit of production is small (Khatkar, 2007). Further, dairying is considered as a subsidiary occupation to our farmers. Limited access to mass media and illiteracy among our farmers are the main causes of ignorance regarding the quality norms and the advantages in producing quality milk. There by the Indian dairy industry is in a highly disadvantaged position in milk market. There is urgent need to educate millions of milk producers to improve the quality of milk and milk products.
In this context, clean milk production is one important aspect in enhancing the quality of milk. Like in adoption of any other innovation, adoption of clean milk production also has to undergo different steps in innovation decision process. First step in this is awareness of the farmer about the practice. It is also important to know his perception about it. Keeping in view this point, this study was undertaken with the objective of understanding perception of dairy farmers about clean milk production.

\section{Material and Methods}

The study was undertaken in six villages of Gadag district in northwestern part of Karnataka state. The study was conducted by survey method. From each village, 30 dairy farmers were selected. Dairy farmers were selected through stratified random sampling. First, dairy farmers were classified into low producing (producing less than 2 liters of milk per day), medium producing (producing 2-5 liters) and high producing (producing more than 5 liters) 
Perceptions of Dairy Farmers of Gadag district of Karnataka state, India regarding Clean Milk Production

Table-1.: Perceptions of dairy farmers related to clean milk production

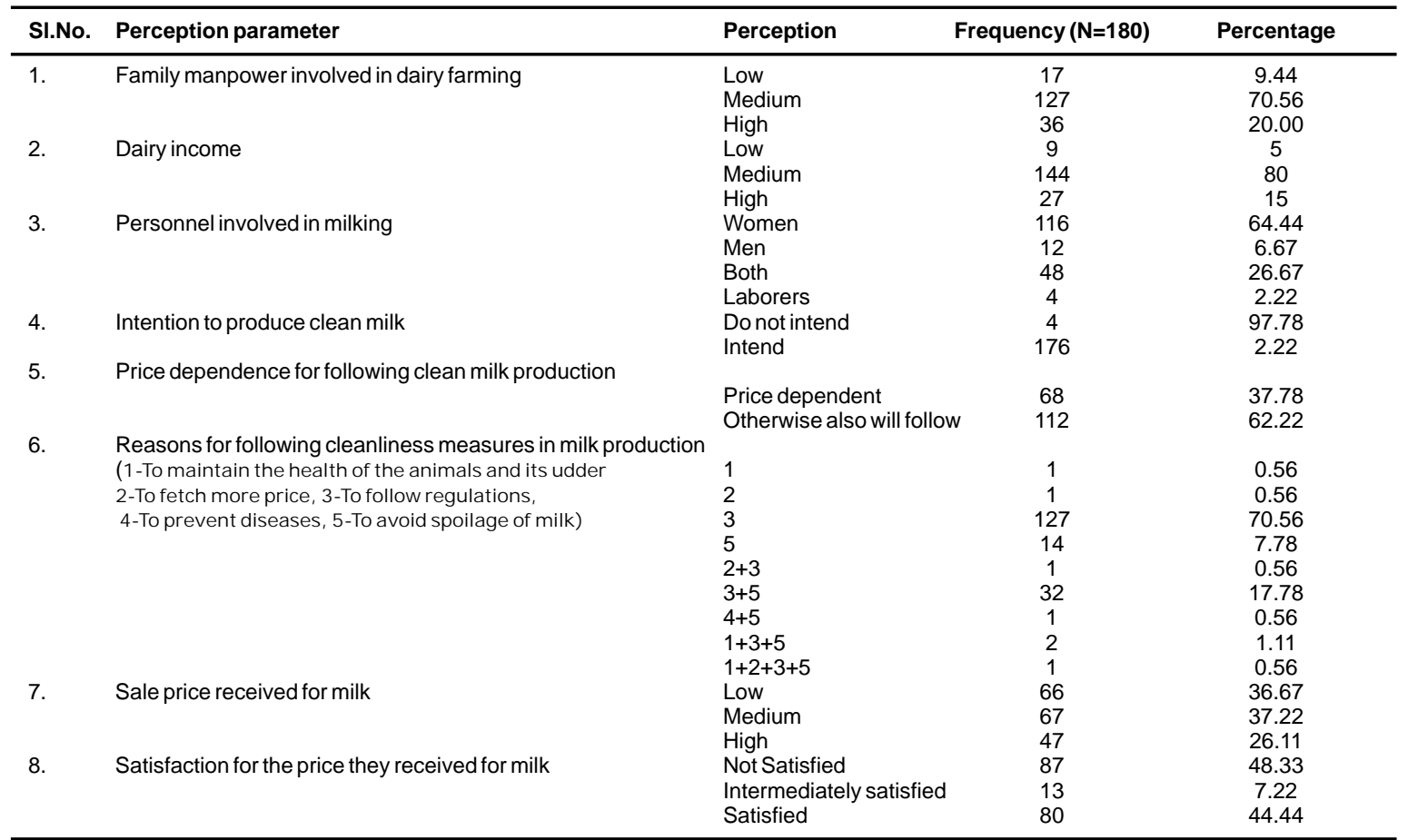

categories. This stratification was made to represent all categories of diary farmers. Within each of these categories, 10 farmers were selected randomly. So, in all there were 180 respondents. Information was collected with the help of a structured interview schedule. Perceptions of the farmers regarding family manpower involved in dairy farming, personnel involved in milking, dairy income, intention to produce clean milk, price dependence for following clean milk production, reasons for following cleanliness measures in milk production, sale price received for milk and satisfaction for the price they received for milk were studied.

\section{Results and Discussion}

Distribution of the respondents in these three main categories according to perceptions of dairy farmers regarding milk production is presented in table 1 .

Family man power involved in dairy farming was predominantly medium to high. In a very few instances, it was low. It means, dairy farming is still at the stage where, it is able to provide employment and income to the farmers. It is not a large scale commercial dairy farming unlike in other developed countries. For over $80 \%$ farmers, dairy farming provided a moderate income as portion of their total family income. It strengthens the argument that dairy farming is still not a specialized activity for a large number of farmers in our country. It is undertaken largely as a component system of crop-livestock system.

Table 1 indicates, milking was mainly a domain of women. Similar findings were observed by Dieckmann (1994). In some families, both men and women milked the animals depending upon the convenience. In some instances, laborers were milking the animals. However, in many training programmes to the dairy farmers, majority of the farmers will be men. However, when it comes to clean milk production, women are needed to be given more importance in training.

Most of the dairy farmers $(97.78 \%)$ expressed their willingness to follow clean milk production measures. Further, these farmers were ready to follow such measures even if they were not paid more price for milk. No doubt, price is an important factor in stimulating the farmers to adopt clean milk production measures. However, it does not seem to be the single determining factor. But, provided the requisite facilities and guidelines from the agencies concerned, farmers were more likely to adopt clean milk 
production practices.

Further, Examination of table 1 reveals, farmers practiced clean milk production measures mainly to follow regulations at the dairy co-operative society (minimum lactometer reading and fat percentage, more dirt was not allowed etc.). The other main reason was to avoid spoilage of milk. Thus, it shows, dairy farmers largely neglected impact of cleanliness on animals' udder and health. They also did not seem to know about milk contamination causing health hazards. On similar lines, Patil et al (2009) reported that majority of the dairy farmers did not know that the milker should be healthy and free from bad habits. This might be because of their ignorance about their personal health and spread of zoonotic diseases through humanly infection via milk. Drawing from the experiences of (Khatkar, 2007), the study suggests for proper education to the farmers regarding importance of clean milk production from health, marketing and animal health point of views.

Among the reasons for following clean milk production practices, price was not mentioned as a reason by most farmers. Because, the milk pricing policy both at dairy co-operative societies and private sectors was largely based on solids and fat content of milk. Concept of pricing based on cleanliness of milk was neither mooted by the market nor by the farmers. Further studies on relationship between pricing policy encompassing microbial quality of milk and cleanliness of milk need to be under taken.

Majority of the producers $(48.33 \%)$ were not satisfied with price they were getting for milk. Even though exact relationship between pricing of milk encompassing microbial quality and cleanliness of milk is not well established, as reported by Mohi and Bhatti (2006), to adopt something new practice like clean milk production, farmers' satisfaction regarding price they get for milk may act as an influencing force.

\section{Conclusion}

Dairy farmers largely neglected impact of cleanliness on animals' udder and health. They also did not seem to know about milk contamination causing health hazards. However, majority of them inclined to follow clean milk production measures. Requisite facilities and guidelines from the agencies concerned are needed to be provided to the dairy farmers to adopt clean milk production practices. Hence, the study suggests for proper education to the farmers regarding importance of clean milk production from health, marketing and animal health point of views. Milking was mainly a domain of women. The study suggests giving more importance to women in dairy farmers' trainings. Majority of the producers were not satisfied with price they were getting for milk. The study also suggests offering satisfactory price for milk to hasten the process of adoption of clean milk production practices by dairy farmers.

\section{References}

1. Dieckmann N. (1994); The integration of social and gender issues in smallholder dairy production. World Animal Review No. 79, FAO, Rome.

2. Khatkar, B.S., (2007) ; Present scenario of quality control of milk in India, In Food science and technology, Daya Books, Pp- $144 \& 153$.

3. Mohi, A.K. and Bhatti, J.S.(2006) ; Adoption of improved dairy farming practices by members of Punjab Dairy Farmers Association, Journal of Dairying, Foods and Home Sciences, 25(1): 55-58.

4. Patil, A.P., Gawande, S.H., Nande,, M.P. and Gobade, M.R. (2009) ; Assessment of knowledge level of dairy farmers in Nagpur district and the co-relation between socio-economic variables with their training needs, Veterinary World, Vol.2(5): 199-201. 